\title{
Salivary Gland Myoepithelial Carcinoma
}

National Cancer Institute

\section{Source}

National Cancer Institute. Salivary Gland Myoepithelial Carcinoma. NCI Thesaurus. Code C35700.

A locally aggressive carcinoma that arises from the salivary glands, predominantly the parotid gland. It is characterized by the presence of a malignant cellular infiltrate which exhibits myoepithelial differentiation. Patients usually present with a painless mass. 